科学問題的投机态度，反对无根据的綜合和奢望包罗 万象的說明。对于科学力量的自豪信念应該与謙觑結 合起来，大䏣的科学概括应該依靠对事实的严格的研 究和对細节的仔細的探討。

因此，䇾如应当防止那种用控制 論 来解 释自然 界、社会及思惟中各种訊息的控制和传递过程的輕率 的要求，其实合理地了解控制論仅仅要求对待这些現 定方面的研究提供充分普遍的和有成效的新方 法。

在历史唯物主义、社会心理学、社会主У社会中 的矛盾等等范畴內曾經提出了和討論了許多一般性的 問題, 而在进行哲学研究的时候却没有不戻其煩地細 心研究事实和細节。但是列宁說明这种态度是形而上 学的、不科学的。列宁和馬克思一样，經常是在深入 研究大量具体的材料的基础上得出結論，因此，这些

諭就成为科学，提高成为极广泛的概括，同时成为 实践中面正的指南。

列宁不仅在科学中及其为爭取科学的一般原則而 奋斗作出了資献，而且列宁的个性，作为一个科学家
来說, 也是至高的范例。作为一个科学家，列宁的特 点是: 第一，完整的、彻底的科学世界覌和对人的䚯 識的强大力量的无限信心; 第二, 概括科学思想的勇 敢和深度，及其与洞察具体事实細节結合的寛度; 第 三，理論和实践的活生生的联系, 科学結論发生效力; 最后, 列宁的根本特点是, 热情、党性、对科学的各 种歪曲的不調和性。这种不調和性与科学的眼界广闊 抹不矛盾，而且正是由之产生的，它是一个面正的科 学家所不可缺少的优良稹品, 因为决不能使潰理与錯 誤調和起来。

經过几十年或者几个世紀，当資本主义早已經是 过去了的事情的时候，資本主义的思想体系及其所有 的唯心主义的、反科学的讕言将消失得无影无踪，同 它們的斗争也将成为过去。但是在从所未有的末来科 学的繁荣中, 列宁对科学所提供的, 所发展的, 所捍 卫的，为了“活生生的、有成效的、合乎面理的、强 大的、具有无限威力的、客覌的、絕对的、人的䚿識” 的进步所作的一切，将永远保持着它的意义。

[葉蒸譯自1960年 4 月 21日苏联“消息报”]

\title{
在自然科学中捍卫唯物主义来紀念 伟大的革命导师列宁
}

\author{
关肇直 \\ （中国科学院数学研究所）
}

在毛泽东思想指导下，在党的社会主义建設总路 栳的光輝照耀下，我国正在以飞快的速度向社会主义 和共产主义迈进。在这侍大的时代里紀念无产阶級革 命的伟大导师列宁，具有无比深刻的意义。

作为自然科学工作者, 特別是数学工作者, 我只 准备談一下自己学习列宁的哲学著作和他关于自然科 学中的哲学問題的光輝指示所获得的一点体会。

列宁在“唯物主义和經驗批制主义”这部伟大的著 作里从該識論上分析了形形色色的唯心主义流派的論 点, 特別彻底批制了那种利用歪曲近代物理学的新发 現来进行唯心主义投机的企图，捍卫了唯物主义，也 保卫了自然科学。列宁継恩格斯之后，在总結最新自
然科学的成果作出正确的哲学結論方面树立了光輝的 典范。

尽管从柏克萊到馬赫这些人已經死了几百年到几 十年，他們所代表的那些形形色色的唯心主义却抹没 有随着消逝。相反，随着西方資本主义社会的衰朽窝 㘳，这些形形色色的唯心主义受到垂死的痹产阶級的 梳治者讲命的栽培，从而日谷取得更为荒誕的 形式。 和阶級斗爭一样，这些唯心主义的垂死反扑还具有非 常瘋狂的性貭。这些唯心主义者宣传不可知諭; 他們 訩为自然科学只能描逝一些人类感覚所接 触 到的 現 象，而不能洞察事物的本稹。他們甚至㟇茂說任何寻 求这些現象所反映的客覌存在一一物稹存在的企图都 
是“形而上学”一一这种所謂形而上学当然絕不是我們 所謂的形而上学。他們歪曲量子力学的成果, 至曲測 不准原理而宣传不可知論和主覌唯心論。他們歪曲現 代量子場論，荒琴地把場和物稹分开、割裂开，把場 看作非物稹的东西，实际上不过是“物盾消灭了，只 剩下方程”这种陈腐监調的翻版。

对于数学，唯心主义者不能訩識到它是研究現实 世界中的量的关柔的科学，看不到由于量和稹的相互 轉化, 这种量的关采的研究也能反映事物的稹; 相 反，他們企图用数学描述代替这种描述所反映的客覌 現实; 不是用函数关系表达客覌规律中的量的关系， 而是用函数关系来代替客覌规律; 不是用方程表达存 在于客覌事物之間的量的关系，而是用方程来代替物 质。这是用数学代替其它科学的企图。另一方面, 也 有把数学和其它科学割裂的企图; 这种人只看到了数 学的高度抽象性这一特点, 把数学从它来自客覌世界 的泉源割断，晾为数学是人类头脑的自由創造。他們 甚至連 “純粹数学” 这一非常片面而不科学的名称都 感筧不满足，而提倡用“自由数学”这样荒謬的名称， 妄图把数学从物稹世界的 “桎棈”下“解放出来”。这 两种表面不同的覌点, 实稹上是同出而异名的唯心主 义。至于把数学看作一种䄪定, 訩为数学沟有什么喧 不埧的問題, 而只有怎样方便的問題, 这种約定論正 是馬赫主义的正宗。和昰曲数学或数理荤輯的成果有 較密切关来的一些現代資产阶級唯心主义流派一一特 别是避輯实証主义，言义哲学等乃是实証主义的新版 或支流。学习列宁的著作对于保卫数学的最新成果, 批制种种唯心主义的丕曲, 在今天有非常 現实的意 义。

在六十年代的中国, 当我們根据毛泽东思想, 党 的科学为无产阶級政治服务, 为社会主义建設服务的
精神而进行数学革命一一包括确立数学发展的正确道 路，根本性地改革数学敉育一一的时候，学习列宁的 哲学著作更是十分必要的。我們所批判的数学中理論 脫离实际的資产阶級学术思想不正是列宁所批判的种 种唯心主义論点的継承嗎?

列宁在“論战斗唯物主义底意义”一文中提出了自 然科学工作者要作战斗唯物主义者的光荣任务。他指 出: “必須記着: 正因为現代自然科学遭遇着急 剧的 变革, 所以往往有大大小小的反动哲学学派和哲学流 派发生。因此，注視着自然科学方面最新革命所提出 的种种問題, 扭吸收自然科学家来参加哲学杂志上所 进行的这种工作，便是一个紧急的任务，战斗的唯物 主义若不解决这个任务，那它就会根本不成其为战斗 性的东西，就会根本不成其为唯物主义。”“我們如果 不愿对这种現像持一种无意識的态度, 就应該 知 道, 任何自然科学，任何唯物主义，若拿不出强有力的哲 学上的論証，就抵挡不住資产阶級覌念底攻古，也阻 止不了資产阶級世界观底复辟。为要支持这个斗争, 为要把这个斗爭进行到底而获得完全胜利, 那末自然 科学家就必須做一个現代的唯物主义者, 做一个馬克 思所代表的唯物主义底自覚信徒, 即須做一个讋証唯 物主义者。”

在六十年代, 当自然科学的发展中心轉移到计会 主义陣营的时候，自然科学的发展更是飞快的; 从而 正如列宁所說: “要知道, 自然科学进步得十分迅速, 在各方面受到极深刻的革命的改变, 所以自然科学没 有哲学的結論是絕对不行的。” 我們用实际行动作一 个战斗的唯物主义者，用䯫証唯物主义覌点对自然科 学的最新成果作出正确的結論, 扵运用䛨証唯物主义 指导自然科学的发展, 就是作为自然科学工作者紀念 伟大的列宁的非常好的方式。

\section{伟大的列宁思想与現代物理学*}

彭 桓 武

伟大的列宁思想把学、塥会科学、自然科学和 无产阶級革命、共产主义建設結合起来，指出人們在 自然、社会、思維各方面活动的正确方向, 促使全面
飞跃的发展。

伟大的列宁思想对二十世紀自然科学的发展起了 历史上划时代的影响。在这資本主义日漸衰亡、社会 